exaustivamente da questão da automação e de seus impactos sobre a organização do trabalho e a sociedade?2 Se tudo isto foi escrito a partir de transformações tecnológicas operadas no século XVIII, como podemos en-

1. Introdução,

2. Automação e flexibilidade nos processos mecânicos de fabricação;

3. Automação e flexibilidade na linha de montagem, 4. Considerações finais.

\section{Automação de base microeletrônica e organização do trabalho na indústria metal-mecânica}

Benedito Rodrigues de Moraes Neto

Professor de economia e organização do trabalho na Escola de Engenharia de São Carlos da Universidade de São Paulo.

\section{INTRODUÇÃO}

Encontramo-nos atualmente em um momento de grande mudança tecnológica ao nível de processos produtivos industriais em função da aplicação da microeletrônica. É tão intensa a transformação técnica recente, que é comum a referência a uma Terceira Revolução Industrial, a Revolução Microeletrônica. Como não poderia deixar de ser, em se tratando de progresso tecnológico ao nivel dos processos, o que se observa é um grande salto no grau de automação industrial, com a introdução da chamada automação de base microeletrônica. Esse fato tem originado fundadas preocupações sobre os impactos da automação, fundamentalmente sobre o nível e a composição do emprego.

Ao verificarmos esse impacto da automação industrial, ficam-nos, todavia, as seguintes questões: não é a automação algo imanente à própria grande indústria? Quando da Revolução Industrial, a introdução maciça da maquinaria (basicamente no setor têxtil) não gerou as mesmas discussões a respeito do emprego da força de trabalho?' Os autores clássicos já não trataram tender o ressurgimento dessa preocupação no último quartel do século XX? Em outras palavras, se a indústria, a partir da emergência do princípio da maquinaria (ou, o que é o mesmo, da automação) na segunda metade do século XVIII, tivesse desenvolvido de forma contínua (ainda que não de forma linear) o grau de automação, seria difícil imaginar que um avanço na automação na atualidade gerasse um impacto tão vigoroso como o que se tem observado (ou antevisto para um futuro recente). Podemos ilustrar essa opinião através da indústria têxtil; se caminharmos do tear mecânico do fim do século XVIII até os teares sem lançadeira dos nossos dias, observaremos uma tendência contínua de avanço do grau de automação, ou seja, do grau de independentização do processo produtivo frente ao trabalho humano. Tendo ocorrido essa persistente elevação da produtividade do trabalho, então em que medida a introdução da microeletrônica na indústria têxtil pode alterar sua natureza técnica? Acreditamos que muito pouco, e que, nesse setor, o impacto da microeletrônica será muito reduzido, evidentemente se considerarmos o padrão mais avançado da indústria. Outro setor importante para ilustrar nosso ponto de vista é o setor químico. A indústria de fluxo contínuo ajusta-se perfeitamente ao princípio da maquinaria, posto que se trata de processo de trabalho cientifizado, objetivado, onde o trabalho imediatamente ligado à produção perdeu radicalmente conteúdo e foi eliminado em grande medida. Nesse caso, a microeletrônica penetra apenas no aperfeiçoamento dos processos de controle, de há muito já automatizados a partir do controle pneumático. Qual a magnitude do impacto dessa mudança nos processos de controle? Muito pequena, pois a indústria química já chegou a um grau de automação que não permite impactos grandiosos sobre o emprego da força de trabalho, já tão reduzido.

Após a ilustração com a têxtil e a química, recolocamos a questão: de onde vem a natureza radicalmente transformadora da automação microeletrônica? Que é uma mudança técnica de grandes proporções na indústria não há dúvida; é necessário, todavia, esclarecer suas razões. Em outras palavras, como uma coisa tão conhecida do capitalismo, como a automação, pode adquirir uma face de coisa tão nova? A resposta parece-nos estar situada no atraso tecnológico da indústria metal-mecânica relativamente aos demais ramos industriais relevantes.

\section{AUTOMAÇÃO E FLEXIBILIDADE NOS PROCESSOS MECÂNICOS DE FABRICAÇÃO.}

Antes de procurarmos esclarecer a idéia do atraso da indústria metal-mecânica, vale esclarecer o que entendemos por automação clássica, ou seja, a automação refletida pelos pensadores clássicos do século XIX. Por um lado, tratava-se da superação da dependência do processo produtivo frente à habilidade dos trabalhadores; por outro lado, só se concebia a automação enquan- 
to automação dedicada ou automação rígida, isto é, ligada à produção, em grande quantidade, de um determinado tipo de produto. A automação de base eletro-mecânica, como é o caso da automação clássica, é necessariamente dedicada. Não existe, nessa base técnica, elementos que permitam ao sistema de máquinas alterar seus movimentos para a fabricação de produtos diferentes. Um tear automático é ajustado para tecer da forma $x$, e terá que produzir grande quantidade para depois sofrer um novo ajuste; uma máquina transfer para produzir uma peça $y$, só faz isso, e terá que fazê-lo em grande escala para ser viável do ponto de vista econômico.

Ora, se automação é sinônimo de automação dedicada (e isto sempre foi assim até o advento recente da microeletrônica), então, por negação, aquilo que necessitasse de flexibilidade não permitiria automação. E a necessidade de flexibilidade sempre foi muito grande nos processos mecânicos de fabricação, não só no caso da produção por encomenda, o que é evidente, mas também na produção seriada, pois o conjunto dos processos mecânicos de fabricação forma uma base produtiva que deve atender a toda uma diversificada necessidade de peças de um dado produto mecânico. Para produzir peças parecidas entre si, não havia como utilizar a automação, que era, como já dissemos, de natureza rígida. Nesse caso, era necessário lançar mão do mais flexível dos instrumentos de produção: o homem. Pela sua própria natureza, "o homem é um instrumento muito imperfeito de produção quando se trata de conseguir movimentos uniformes e contínuos" ; ${ }^{3}$ e é, ao mesmo tempo, o mais perfeitamente flexível de todos os elementos da produção. Isto em função do seu sistema sensorial extremamente desenvolvido. Chegamos assim à chamada máquina universal, cujo representante mais conspícuo é o tornó manual, o qual deve ser considerado uma ferramenta e não uma máquina stricto sensu. Isto porque a função da máquina, desde seu aparecimento e grande difusão nos séculos XVIII e XIX, sempre foi o de substituir a ação humana no processo produtivo; ora, o torno manual não substitui a ação humana, e sim faz a necessária mediação entre homem e matéria, como, por exemplo, o cinzel do escultor. Bastante esclarecedor sobre o caráter da máquina-ferramenta universal é o seguinte trecho do jornal Folha de São Paulo, 18 abr. 1982: "O desenho de uma peça representa uma memória com todas as informações necessárias para a usinagem, ou seja, onde deve ser desbastada, furada ou rosqueada. Em um torno ou fresadora convencional, esse desenho deve ser interpretado pelo homem, já que a máquina não entende o desenho."

Como podemos observar, é o sistema sensorial extremamente desenvolvido do ser humano que o capacita a atuar como elo de ligação entre o desenho e a peça. As inforınações contidas no desenho são captadas pelo cérebro humano, que a partir daí ajusta o torno segundo as especificações necessárias. Consegue-se assim grande flexibilidade produtiva, pois o torneiro, evidentemente, lê quaisquer desenhos de peças.

Somente através do desenvolvimento da microeletrônica foi possível quebrar aquele esquema automação dedicada/não-automação flexível. Isto porque, sabidamente, a microeletrônica permitiu a geração de equipa- mentos que passaram a ter, em alguma medida, faculdades antes monopolizadas pelo homem. Vejamos novamente a mesma matéria do jornal Folha de São Pau$l o, 18$ abr. 1982, referindo-se agora às máquinas-ferramenta de controle numérico: “(...) a necessidade de fazer pequenos lotes de peças diferentes entre si, com grande precisão, e que liberasse o homem do controle do centro de usinagem, levou à criação de um equipamento destinado a conversar com a máquina ou servir de intérprete entre o desenho da peça e a linguagem da máquina."

A automação não é mais sinônimo de automação rígida ou dedicada; passa-se a ter, ao lado do mesmo conceito de automação, qual seja, produção material sem interveniência direta do trabalho humano, duas formas dessa automação: dedicada e flexível.

É desde logo evidente que a introdução da microeletrônica nos bens de capital exerce um impacto imenso na indústria mecânica, dada a importância das máquinas-ferramenta universais. Esse impacto se observa tanto no que diz respeito ao nivel de emprego como no que se refere à natureza da força de trabalho ocupada. Isto porque a natureza da máquina-ferramenta universal leva inexoravelmente à necessidade de um trabalhador qualificado, cuja formação gua:da analogias com o artesanato medieval. Como afirma J. R. Tauile: “(...) as máquinas-ferramenta universais são flexíveis e versáteis para atender à produção de unidades, lotes e pequenas séries de peças diversas e freqüentemente complexas. Eram exatamente essas características das MFU que exigiram as melhores qualificações, principalmente habilidades manuais e experiência dos seus operadores." 4 A transformação que se opera com o controle numérico é radical; o torno ou a fresa, por exemplo, passam a ser máquinas no sentido rigoroso do termo, e, como conseqüência, tornam a produção independentizada das habilidades do trabalho imediatamente aplicado à produção, como fíca claro nesse trecho do jornal Data News de 12 jul. 1983: "Com a utilização de MFCN, todas as informações que compõem o projeto de engenharia de uma peça, bem como as informações sobre o tipo de ferramenta a ser utilizado e sua trajetória (locação, velocidade etc.) ao longo dos eixos de corte sobre a peça, são transformadas em representações matemáticas. As instruções de operação são então codificadas em uma fita perfurada ou outro 'midia'. Feito isso, o programa (desde que devidamente testado) está pronto para ser colocado na máquina (no gabinete do $\mathrm{CN}$ ) por seu operador. Tauile defende em sua tese que o trabalho deste operador fica agora reduzido a 'alimentar' o equipamento com a peça em bruto e com as devidas ferramentas, 'zerar' a máquina antes do início da operação, apertar o botão de partida e vigiar o processo de modo a paralisá-lo na eventualidade de desgaste excessivo da ferramenta e de quebra do equipamento."

Valem agora, e só agora, para a usinagem, as seguintes colocações de Marx sobre a "apendicização" do homem à máquina, válidas para a indústria têxtil desde o século XVIII: "A máquina-ferramenta é um mecanismo que, uma vez que se lhe transmite o movimento adequado, executa com suas ferramentas as mesmas operações que antes executava o trabalhador com outras 
ferramentas semelhantes."' "A máquina já não tem nada de comum com o instrumento do trabalhador individual. Distingue-se por completo da ferramenta que transmite a atividade do trabalhador ao objeto. De fato, a atividade manifesta-se muito mais como pertence da máquina, ficando o operário a vigiar a ação transmitida pela máquina às matérias-primas, e a protegê-la das avarias." "Tão logo a máquina possa executar sem ajuda do homem todos os movimentos necessários para elaborar a matéria-prima, ainda que o homem vigie e intervenha de vez em quando, teremos um sistema automático de maquinaria." 7

A partir das máquinas-ferramenta de controle numérico, chega-se às formas mais desenvolvidas da indústria mecânica, os Módulos Flexíveis de Manufatura (FMM), as Células Flexíveis de Manufatura (FMC) e os Sistemas Flexíveis de Manufatura (FMS). Vejamos resumidamente o que vêm a ser essas formas, seguindo a caracterização fornecida por Moussa Simhon: "Com a sigla FMM - Módulo Flexível de Manufatura - se define um sistema que consiste de uma máquina CNC estimulada por um robô, usado para carga e descarga de uma grande variedade de peças, projetado para trabalhar entre oito e doze horas sem interferência humana. Não se trata, aqui, de um sistema controlado por um computador central, mas sim de um sistema de máquinas para a produção de peças médias e pequenas (...). Já o FMC, ou sistema de célula flexível de manufatura, consiste de dois ou mais comandos numéricos computadorizados equipados com um sistema robotizado para a transferência automática de uma larga variedade de peças em cada máquina. Esse sistema, que também não é controlado por um computador central, é capaz de operar, sem a interferência do homem, durante oito ou doze horas (...). O FMS é um sistema de controle centrado por computador formado por duas ou mais máquinas CNC equipadas com um sistema robotizado para a transferência automática de peças de uma máquina para outra, também com capacidade de operar por longas horas sem qualquer interferência humana. O computador central controla a produção desde o suprimento de material até a finalização do processo, de acordo com um programa (de produção) armazenado em sua memória. Em outras palavras, o FMS executa a usinagem de uma larga variedade de peças, em pequenos lotes, durante horas ininterruptas, sem a interferência humana na operação, e em sequiência de produção programada."'8

Observamos que, com a adição de robôs, um conjunto de MFCN dá origem ao que Marx denomina "sistema automático de maquinaria", com a especificidade, esta sim nova, de ser um sistema automático de maquinaria flexivel.

\section{AUTOMAÇÃO E FLEXIBILIDADE NA LINHA DE MONTAGEM}

Continuemos com nossa argumentação em torno da natureza tecnicamente atrasada da metal-mecânica. Já nos referimos aos processos de fabricação mecânica, mais especificamente à usinagem. Passemos agora a outro setor típico e fundamental da indústria metal-mecânica: a linha de montagem fordista. Trabalhamos sobre esta forma de organização do trabalho em nossa tese de doutoramento e chegamos a concluir, para colocar de forma sucinta, que a linha de montagem fordista não se caracteriza como um desenvolvimento da maquinaria, e sim como um "desenvolvimento brutal das características próprias do trabalho sob a forma manufatureira".9 Trata-se da forma mais desenvolvida de "uma máquina cujas peças são homens", para usar a clássica definição dada por Ferguson para a manufatura. Esta natureza da linha de montagem é outro componente (e fundamental) do atraso tecnológico da metal-mecânica relativamente a outros setores (como, por exemplo, têxtil, química e siderurgia). Todavia, ocorre uma diferença fundamental relativamente ao atraso do setor de fabricação, pois a linha de montagem fordista implicou uma imensa desqualificação da força de trabalho e uma grande utilização de mão-de-obra não-qualificada.

A revolução tecnológica da montagem terá um impacto imenso do ponto de vista quantitativo, dado que os setores que abraçaram o fordismo ganharam um peso relativo bastante alto na estrutura industrial capitalista no pós-guerra (bens de consumo duráveis em geral.)

Aprofundemos um pouco a questão da desqualificação da força de trabalho sob a linha de montagem. $\mathrm{Na}$ medida em que se fundamenta no trabalho parcelar, e procura fixar o homem num determinado posto de trabalho, fazendo, sempre que possivel, "uma só coisa com um só movimento", 10 a linha de montagem implica absorção maciça da mão-de-obra não-qualificada.

Sobre esse ponto esclarece Henry Ford: "Quanto ao tempo necessário para a aprendizagem técnica, a proporção é a seguinte: $43 \%$ não requerem mais que um dia; 36 requerem de um dia até oito; seis, de uma a duas semanas; 14, de um mês a um ano; um, de um a seis anos. Esta última categoria de trabalhos requer grande perícia - como a fabricação de instrumentos e a calibragem." (Observe-se que 1\% dos trabalhos que requerem grande perícia não estão incluídos na montagem.) $)^{11}$

Todavia, a desqualificação do trabalho em linha de montagem é de natureza radicalmente diferente da desqualificação do trabalho "apendicizado"' à máquina. Nesse último caso, como os movimentos não partem dos trabalhadores, mas das máquinas, 0 "trabalho vivo encontra-se subordinado ao trabalho materializado, que age de modo autônomo". ${ }^{12}$ Nesse caso, "o conjunto do processo de produção já não está, então, subordinado à habilidade do operário: tornou-se uma aplicação tecnológica da ciência"'.13

É por essas características do trabalho "apendicizado" à máquina que Marx chega à consideração de que "o operário é supérfluo". Como vemos em A. Palma: "a máquina, como contraproposta à ferramenta artesanal é um mecanismo passível de um processo indefinido que passo a passo conduz à restrição da área de trabalho do trabalhador e, como limite, esvazia de conteúdo esse trabalho. Deste ponto de vista, as operações manuais propriamente ditas não são senão resíduos passíveis de mecanização quando se produzam novas modi- 
ficações tecnológicas e, como resíduos, não têm importância para o estudo da organização da fábrica"'.14

Já a linha de montagem fordista consegue "destituir o trabalho de qualquer conteúdo, mantendo ao mesmo tempo a ação manual do trabalhador sobre o objeto de trabalho através das ferramentas". 15 Dessa forma, ainda que o capital se independentize das " habilidades dos trabalhadores, não os torna supérfluos, mas os exige em grande quantidade, para atuarem como 'autômatos úteis' no lugar dos elementos inanimados da máquina". 16 Ao invés de serem "resíduos passiveis de mecanização", as tarefas manuais de caráter extremamente simplificado constituem a base mesma do processo de trabalho. Cabe a pergunta: se são desprovidas de conteúdo, extremamente simplificadas, então por que não são facilmente mecanizadas? Ocorre que as tarefas de montagem são extremamente simples tendo em conta o potencial de ação do ser humano, ou seja, para o homem, com seu sistema sensorial extremamente desenvolvido, as tarefas de montagem são simples; todavia, " a complexidade dos gestos a efetuar (trajetórias espaciais precisas que exigem torções de forças extremamente compilexás e variáveis) é tal que não pôde até agora ser 'incorporada' 'a priori nem a uma máquina especial clássica, nem mesmo a uma máquina programada" . ${ }^{17}$ Em resumo, se são tarefas simples para o homem-máquina, são tarefas muito complexas para a máquina. Isto porque a máquina, tal como caracterizada classicamente por Marx, “tomou para si, desde seu nascedouro, a função de 'modelar o objeto trabalhado', no sentido da realização das transformações necessárias à transformação do objeto de trabalho em produto do trabalho"'.18 Já a produção de um produto, como por exemplo (e é o exemplo mais rico) o automóvel, que se constitui na junção de milhares de componentes, não pode, evidentemente, ser realizada à base da máquina em sua acepção clássica. Conseqüentemente, para conformar a linha de montagem à característica genérica da produção à base de maquinaria (transformar a linha de montagem em um sistema de máquinas) é necessário um novo tipo de máquina, filha do desenvolvimento da microeletrônica: $o$ robô.

Já vimos o robô articulado com MFCN nos FMM, FMC e FMS; agora vemos o robô como a máquina por excelência da montagem automatizada, e devemos, antes de mais nada, procurar defini-lo. A definição considerada melhor pelos especialistas é a da Robotics Industries Association (RIA): "um robô é um manipulador programável multifuncional projetado para mover materiais, peças, ferramentas ou dispositivos especializados através de movimentos programados variáveis a fim de desempenhar uma variedade de tarefas". Esta definição explicita as características fundamentais do robô: por um lado, é um manipulador que fornece ao robô sua natureza específica, pois, como afirma Tauile, "um robô difere de outras formas de automação por sua habilidade de mover um objeto pelo espaço, enquanto que ao mesmo tempo reorienta sua posição";19 por outro lado, é reprogramável e multifuncional, característica genérica de todo equipamento de base microeletrônica, o que implica aquilo que já vimos, ou seja, a automação flexível. Então, se a montagem, pela sua natureza, só pode ser automatizada pela via da ro- botização, e se o robô é, também por sua natureza, flexível, então a linha de montagem automática é necessariamente flexível. Esta conclusão pode, para alguns, levar a uma outra, a de que a automatização da linha de montagem através de robôs representaria uma superação da automação clássica ou dedicada em direção à nova automação, flexível. É o que vemos num trabalho recente sobre o impacto da microeletrônica na indústria automobilística brasileira: "Mas a linha de montagem fordista é mais uma expressão da automação clássica (dedicada) do que da automação microeletrônica (flexível)."'20 Trata-se de um grande equívoco, pois linha de montagem fordista e automação são coisas diametralmente opostas. Como a linha de montagem não tem absolutamente nada a ver com a automação clássica ou dedicada, e utiliza de forma intensiva o instrumento de produção mais flexível, que é o homem, então ela não é rígida. Mais uma vez aconteceu de a linha de montagem mostrar algo que contraria sua natureza; como sua gênese e seu grande desenvolvimento estiveram vinculados à produção em massa de produtos padronızados ("standartizados"), então ficou assentado que a linha de montagem seria "mais uma expressão da automação clássica (dedicada)". Evidentemente, é muito mais simples abastecer uma linha de montagem para a produção em grande quantidade de um produto homogêneo. Mas isto se deve à dificuldade de ordem organizacional, e nunca a uma dificuldade de ordem técnica. Tecnicamente, a linha de montagem e uma manufatura sofisticada, fundando-se exclusivamente no trabalho manual; ora, o sistema sensorial do homem é extremamente desenvolvido, e não existe problema algum em montar num determinado momento um carro tipo $x \mathrm{e}$ num momento seguinte um carro tipo $y$, desde que exista o abastecimento adequado para tal. Isto ficou demonstrado inequivocamente através do sistema kanban (justin-time), que se desenvolveu largamente no Japão, a partir da segunda metade da década de 70 . Este sistema consegue tornar flexível a produção em linha de montagem sem necessitar de qualquer mudança técnica, realizando apenas uma mudança importante na organização da produção. É claro que, se como já vimos, a automatização da linha se dá necessariamente de forma flexível, então a linha automatizada também se ajusta perfeitamente à natureza do kanban.

Vejamos agora qual a natureza de uma linha de montagem automatizada, ilustrando mais uma vez com a indústria automobilística. No jornal Folha de São Paulo, numa matéria intitulada As maravilhas do galpão 54, lemos o seguinte: “'dois pequenos dedos mecânicos escolhem uma correia de alternador, ao lado de várias outras, de diversos modelos e medidas. Lenta e seguramente, as 'mãos' aproximam-se do motor e instalam a correia de borracha. Com um gesto quase humano. As imagens do galpão 54 (da Volkswagen alemã) já fazem parte do século 21 (...). Algumas máquinas em especial assustam. Uma delas, responsável pela montagem da parte superior dos motores, possui uma célula fotoelétrica que lhe permite identificar o tipo de motor, para então escolher as peças compatíveis com ele. Isto entre 150 alternativas disponíveis".

O espanto do jornalista com o galpão 54, com a realidade ou possibilidade iminente de uma linha de mon- 
tagem inteiramente automatizada, é muito significativo. Caracteriza o espanto dos observadores para com transformações tecnológicas de grande profundidade. Lembramo-nos das observações extremamente interessantes de um tal Sr. Perrault acerca do tear para tecer meias (stocking-frame) inventado por William Lee em 1598 , citadas no verbete meia da enciclopédia, escrito por Diderot: "Aqueles que têm gênio suficiente não para inventar coisas idênticas, mas para as compreender, caem num profundo espanto perante o número quase infinito de molas de que se compõe a máquina de fazer meia, e do grande número dos seus diversos e extraordinários movimentos. Quando se vê fazer meias, admira-se a leveza e a destreza das mãos do operário, embora ela faça apenas uma malha de cada vez; como é diferente quando se vê uma máquina que forma centenas de malhas simultaneamente, quer dizer, que faz no mesmo momento todos os vários movimentos que as mãos só conseguem fazer em várias horas! Quantas pequenas molas puxam a seda para si, largando-a, retomando-a, fazendo-a passar de uma malha para outra de forma inexplicável? E tudo isto sem que o operário que movimenta a máquina compreenda nada, saiba nada, ou sequer sonhe o que se passa: é nisso que pode ser comparada à mais excelente máquina que Deus fez (...).'”21

Lembramo-nos também do relato de um jornalista acerca das transformações radicais sofridas pela indústria do aço nos EUA, na virada do século XIX para o século XX, com a introdução do forno Siemens-Martin, transcrito por Katherine Stone: "É em Homestead que prodígios são realizados, tão deslumbrantes quanto os das Mil e uma noites. Aqui, máquinas dotadas de uma força de 100 gigantes movem-se obedientes a um toque, abrindo portas de fornalhas, levantando das chamas vivas enormes chapas de aço incandescentes, mais ou menos como uma criança levantaria uma caixa de fósforos da mesa. Duas destas máquinas, chamadas apropriadamente pelos trabalhadores de 'Leviatã' e 'Behemoth', parecem dotadas de inteligência. Cada uma delas é servida por um pequeno carro elétrico que corre ocupadamente de um lado para outro, com seus movimentos controlados pelo monstro mais lerdo. Este pequeno serviçal pode estar num extremo da longa oficina e o Leviatã no outro; mas, tão logo parece enxergar seu gigante dono abrir a porta da fornalha e introduzir sua enorme mão para receber um novo pedaço de aço quente, então ele retorna feito um cachorrinho para seu dono e chega justamente no momento em que o enorme punho desloca-se com a fulgurante crosta de fundição: o Leviatã então gentilmente coloca esta crosta sobre as costas de seu auxiliar, e, para admiração de todos os espectadores, o pequeno aparelho caminha alegremente com o material para o fim do prédio da fábrica. Mesmo assim, continuam as surpresas; assim que o pequeno ajudante livra-se da crosta, a massa incandescente, duas vezes maior que uma grande mala de viagem, desliza em direção a uma plataforma rolante que a conduz à laminação. E nenhuma mão humana é vista em toda a operação."'22

Mais uma vez, agora em nossos dias, a emergência do sistema de maquinaria, da produção cientifizada, objetivada, assusta os observadores. A nós assusta, isto sim, que a automação ainda assuste! Isto se deve, no nosso juízo, ao fato de que a linha de montagem, que se caracteriza como um desenvolvimento, até o paroxismo, da produção manufatureira, através de introdução da microeletrônica (robotização), ajusta-se abruptamente ao princípio da maquinaria estabelecido por Marx. Em outras palavras, com a robotização, "a linha de montagem transforma-se em um sistema de máquinas". 23

\section{CONSIDERAÇÕES FINAIS}

A natureza técnica da indústria metal-mecânica, tanto no que se refere aos processos mecânicos de fabricação, como no caso das linhas de montagem, aliada ao peso relativo deste setor nas economias capitalistas com industrialização relevante, explicam o intrigante fato de que uma questão do século XIX, qual seja, os efeitos da automação sobre o emprego, volte a ganhar relevância nos dias atuais. O revolucionamento ocasionado pela aplicação da microeletrônica nos processos industriais é de caráter parcial, com efeitos concentrados na metal-mecânica; sua conseqüência será a de trazer essa indústria para o leito da automação, no qual já caminham há muito tempo ramos industriais tecnologicamente mais avançados. Está coberto de razão, portanto, o Prof. A.C.C. Fleury, quando afirma que "a tendência atual é uma concepção de sistemas em fluxo para praticamente todos os tipos de produção, mesmo quando as quantidades a serem produzidas são pequenas"'.24

\footnotetext{
${ }^{1}$ Cf. capítulo XXXI dos Princípios de Ricardo, intitulado Sobre a maquinaria, e o item 6 do capítulo XIII de $O$ Capital, intitulado A teoria da compensação aplicada aos trabalhadores deslocados pelas máquinas.

2 Cf. capítulo XIII de $O$ capital (Maquinaria e grande indústria), v. II dos Grundrisse (itens O processo de trabalho, Maquinaria e trabalho vivo, Contradição entre a base e desenvolvimento da produção e Significado do desenvolvimento do capital fixo) e capítulo I de The philosophy of manufactures, de Andrew Ure.
}

3 Marx, K. El capital. 8. ed. México, Fondo de Cultura Económica, 1973. p. 306.

${ }^{4}$ Tauile, J.R. Microeletronics, automation and economic development. New York, New School for Social Research, 1984. Tese de doutoramento. Transcrito em Professor vê compensações com funções novas. Data News, 12 July 1983. p. 25. Cf. também, de Tauile, J.R. Máquinas-ferramenta com controle numérico (MFCN) e seus efeitos sobre a organizaçāo do trabalho. Instituto de Economia Industrial/UFRJ, out. 1983.

5 Marx, K. op. cit. p. 304. 
6Marx, K. Elementos fundamentales para la crítica de la economía política (grundrisse) 1857-1858. 7. ed. México, Siglo Veíntiuno, 1978. p. 218.

${ }^{7}$ Marx, K. El capital. op. cit. p. 311.

8 Simhon, M. Princípios dos sistemas flexiveis. Máquinas e metais, p. 42-4, jan./fev. 1986.

9 Moraes Neto, B.R. Marx, Taylor, Ford - uma discussão sobre as forças produtivas capitalistas. Tese de doutoramento. Campinas, Universidade Estadual de Campinas, Instituto de Economia, 1984. p. 54.

10 Ford, Henry. Minha vida e minha obra. Rio de Janeiro/São Paulo, Nacional, 1926. p. 78.

11 Id. ibid. p. 105.

12 Karl. Marx, Elementos fundamentales... op. cit. p. 221.

13 Id. ibid.

14 Palma, A. La organización capitalista del trabajo em El capital de Marx. In: Palma, A. et alii. La división capitalista del trabalho: Córdoba, 1972. p.38. (Cuadernos de Pasjado y Presente, n.32.)

15 Moraes Neto, B.R. op. cit. p. 48.

16 Id. ibid.

17 Lafont, J.; Leborgne, D. \& Lipietz, A. Redéploiment industriel et space économique. Paris, Cepremap, 1980. p. 117.

18 Moraes Neto B. R. op. cit. p. 58.

19 Tauile, J.R. O desenvolvimento internacional da robótica: dados e reflexões. IEI/UFRJ, ago. 1985. p. 4, mimeogr.

20 Peliano, J.C. et alii. Impactos económicos e sociais da tecnologia microeletrónica da indústria brasileira - estudo de caso na montadora "A" de automóveis. Brasília, CNRH/Ipea, 1985. p. 22.

21 Vários autores. A enciclopédia - textos escolhidos. Lisboa, Estampa, 1974. p. 123-4.

22 Stone, K. The origins of job structures in the steel industry. In: Edwads, R., Reich, M. \& Gordon, D. ed. Labor market segmentation, Boston, D.C. Heath, p. 36. (No original: "It is at Homestead that wonders are performed as amazing as those of the Arabian Nights. Here machines endowed with the strength of a hundred giants move obedient to a touch, opening furnace doors and lifting of the glowing flames enormous slabs of white-hot steel, much as a child would pick up a match-box from the table. Two of these machines, appropriately named by the men 'Leviathan and Behemot', seemed gifted with inteligence. Each is attended by a little trolley-car that runs busily to and fro, its movements controlled by the more sluggish monster. This little attendant may be at one end of the long shed and the Leviathan at the other; but no sooner does it seem to see its giant master open a furnace door and put in his great hand for a fresh lump of hot steel, than it runs back like a terrier to its owner and arrives just as the huge fist is withdrawn with a glowing scab. This the Leviathan gently places on its attendant's back; and, to the admiration of all beholders, the little thing trots gayly off with it to the end of the building. Even then the wonder is not ended; for the little fellow gives a shake to his back, and the glittering mass, twice as big as a Saratoga trunk slides onto a platform of rollers which carry it to the mill. And no human hand seen in the operation."

23 Moraes Neto, B.R. \& Gomes e Silva, F.L. A linha de montagem no final do século. EESC-USP p. 3, mimeogr.

24 Fleury, A.C.C. Organização do trabalho na indústria: recolocando a questão nos anos 80. In: Fleury, M.T.L. \& Fischer, R.M. coord. Processo e relaçōes de trabalho no Brasil. São Paulo, Atlas, 1985. p. 57.

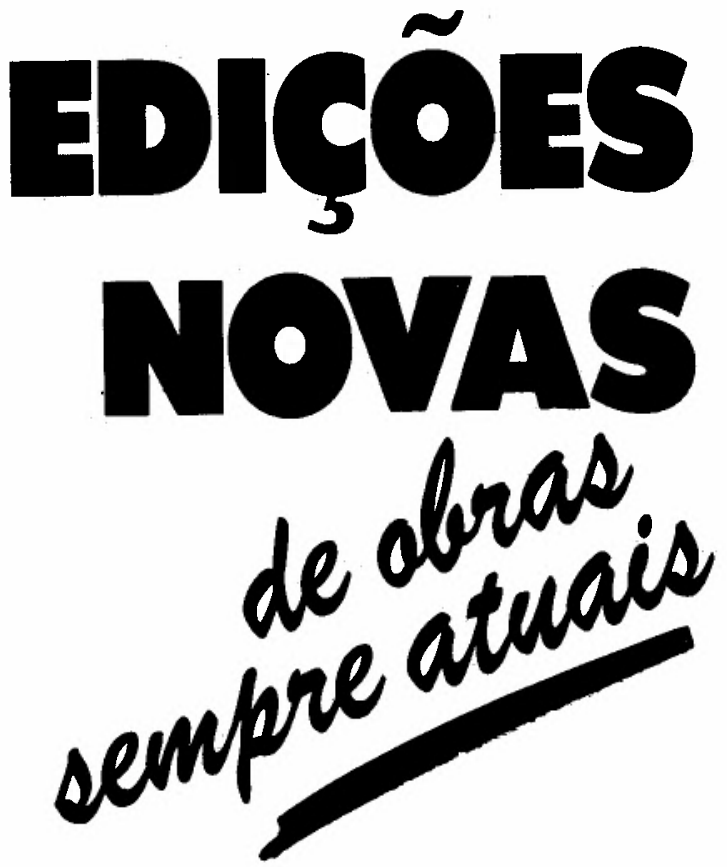

Arte de Apresentar Idéias Novas Eugène Raudsepp

3: Edlção - 1986 - Cz\$ 50,00

Provas Objetivas, Discursivas, Orais e Práticas

Técnicas de Construção

Ethel Bauzer Medeiros

8: Edição - 1986 - Cz\$ 29,00

Uma Análise das Teorias

de Organização

Beatriz M. de Souza Wahrlich

5. Edição - 1986 - Cz\$70,00

Organização e Métodos

Harry Miller

12: Edição - 1986 - Cz\$ 35,00

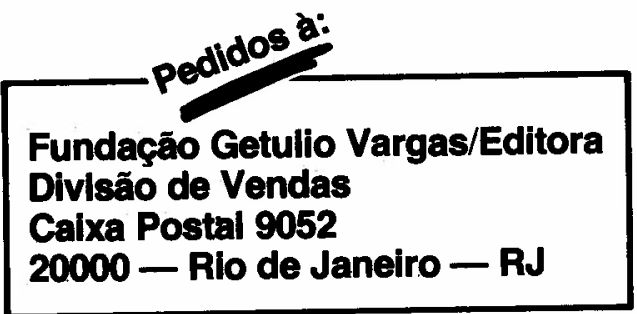

